\section{Simultaneous Spectrophotometric Estimation and Validation of Domperidone, Tramadol Hydrochloride and Acetaminophen in Tablet Dosage Form}

\author{
Vikas Jain and *Rajesh Sharma \\ School of Pharmacy, Devi Ahilya University, Madhya Pradesh, India.
}

\section{${ }^{*}$ Corresponding author:}

Dr. Rajesh Sharma

School of Pharmacy

Devi Ahilya University

Takshshila Campus

Khandwa Road, Indore, M.P. India-452017.

Contact No.: 094254-78418

E-mail: rbsm73@yahoo.co.in

Received - 05 December 2009

Accepted for Publication - 02 March 2010

\begin{abstract}
Simultaneous estimation of active ingredients in multi-component pharmaceutical products normally requires the use of separation techniques, such as HPLC, HPTLC or GC, followed by their quantitation. Presented here are two spectrophotometric methods that do not require prior separation for simultaneous estimation of three drugs; acetaminophen, tramadol hydrochloride and domperidone in a tablet formulation. Shimadzu UV 1700 capable of multi-component analysis was used for quantitation. Method A is based on the simultaneous equation and method $B$ on the multi-component analysis. The absorption maxima of the drugs found to be at $244 \mathrm{~nm}, 271.5 \mathrm{~nm}$ and $284.5 \mathrm{~nm}$ respectively for acetaminophen, tramadol hydrochloride and domperidone in methanol/0.1 N HCl (1:2) solvent mixture. Acetaminophen, tramadol hydrochloride and domperidone obeyed Beer's law in the concentration range of $2-22 \mu \mathrm{g} / \mathrm{ml}, 10-55 \mu \mathrm{g} / \mathrm{ml}$ and $30-300 \mu \mathrm{g} / \mathrm{ml}$ respectively. The simultaneous equation method is based on the additivity of absorbances and multi-component analysis involves recording of absorbances of standard solutions at $244 \mathrm{~nm}, 250 \mathrm{~nm}, 271.5 \mathrm{~nm}$ and $284.5 \mathrm{~nm}$. These were processed by means of statistical calculations and results of sample solution were obtained. Result of analysis for both methods were tested and validated for various parameters according to ICH guidelines.
\end{abstract}

Key Words: simultaneous equation method, multicomponent analysis, acetaminophen, tramadol hydrochloride, domperidone.

\title{
INTRODUCTION
}

Acetaminophen (AMP), N-Acetyl-p-aminophenol, is a para-aminophenol derivative, has analgesic and antipyretic properties and weak anti-inflammatory activity (Martindale, 2002). Domperidone (DOM), 5-chloro-1-[1-\{3-(2-oxobenzimidazolin-1-yl) propyl\}-piperidyl]benzimi- dazolin-2-one, is a dopamine antagonist ( Merck Index, 2001). It is used as an antiemetic for the short term treatment of nausea and vomiting of various aetiologies, including that associated with cancer therapy and with levodopa and bromocriptine therapy for parkinsonism. Tramadol hydrochloride (TRA), ( \pm )cis2-[(dimethylamino)methyl]-1-(m-methoxyphenyl)cyclohexanol hydrochloride, is a centrally acting analgesic indicated for medium intensity short lasting pain due to diagnostic procedures, injury, surgery etc. as well as for chronic pain including cancer pain (Tripathi, 2004). The combination of AMP, TRA and DOM is indicated in trauma, acute low back pain, acute musculoskeletal pain and in sports injury.

AMP and DOM are official in IP (Indian Pharmacopoeia, 1996) and BP (British Pharmacopoeia, 2002) whereas TRA is not official in any pharmacopoeia. An extensive literature survey reveals that many UV (Srinivasan et al, 2007), (Garg et al, 2007), (Puranik et al, 2006) HPLC (Gopinath et al, 2007) (Kucuk et al, 2005), (Gangcheng et al, 2005), (Celma et al, 2000) and HPTLC (Gandhimati et al, 2007) methods are reported for the simultaneous estimation of AMP, TRA and DOM in single and in combined dosage form with other drugs but so far, not a single method has been reported for simultaneous estimation of AMP, TRA and DOM in tablet dosage form. So the need was felt to develop simple, economical, rapid, precise and accurate methods to analyze the drugs simultaneously. 


\section{MATERIALS AND METHODS}

UV/Visible double beam spectrophotometer (Shimadzu Model 1700) was employed with spectral bandwidth of $1 \mathrm{~nm}$ and wavelength accuracy of $0.3 \mathrm{~nm}$ (with automatic wavelength correction with a pair of $1 \mathrm{~cm}$ matched quartz cells). Pure samples of AMP and DOM were obtained from Zest pharma pvt. Ltd., Indore, M.P., India and TRA was obtained from Ranbaxy Laboratories, Dewas, M.P., India. The tablet dosage form, TRAMAZAC-PD Manufactured by Surien Pharmaceuticals, R.S. NO. 4/1, Kurumbapet Village, Villiyanur Commune, Pondicherry, India (Label claim: $37.5 \mathrm{mg}$ TRA, 325mg AMP and 10mg DOM) was procured from the local market. Methanol AR and $\mathrm{HCl} A R$ were obtained from Merck Limited, Mumbai, India.

\section{UV-Spectrophotometry}

Standard stock solution of AMP, TRA and DOM were prepared separately by dissolving $100 \mathrm{mg}$ each (accurately weighed) of standard AMP, TRA, and DOM in methanol/0.1N HCl (1:2) and made up the volume up to $100 \mathrm{ml}$ with same solvent. Working standard solutions of $10 \mu \mathrm{g} / \mathrm{ml}$ of AMP, $30 \mu \mathrm{g} / \mathrm{ml}$ of DOM, and $50 \mu \mathrm{g} / \mathrm{ml}$ of TRA were further prepared by appropriate dilution of standard stock solutions. Overlain spectra of AMP, TRA and DOM were scanned (Figure 1).

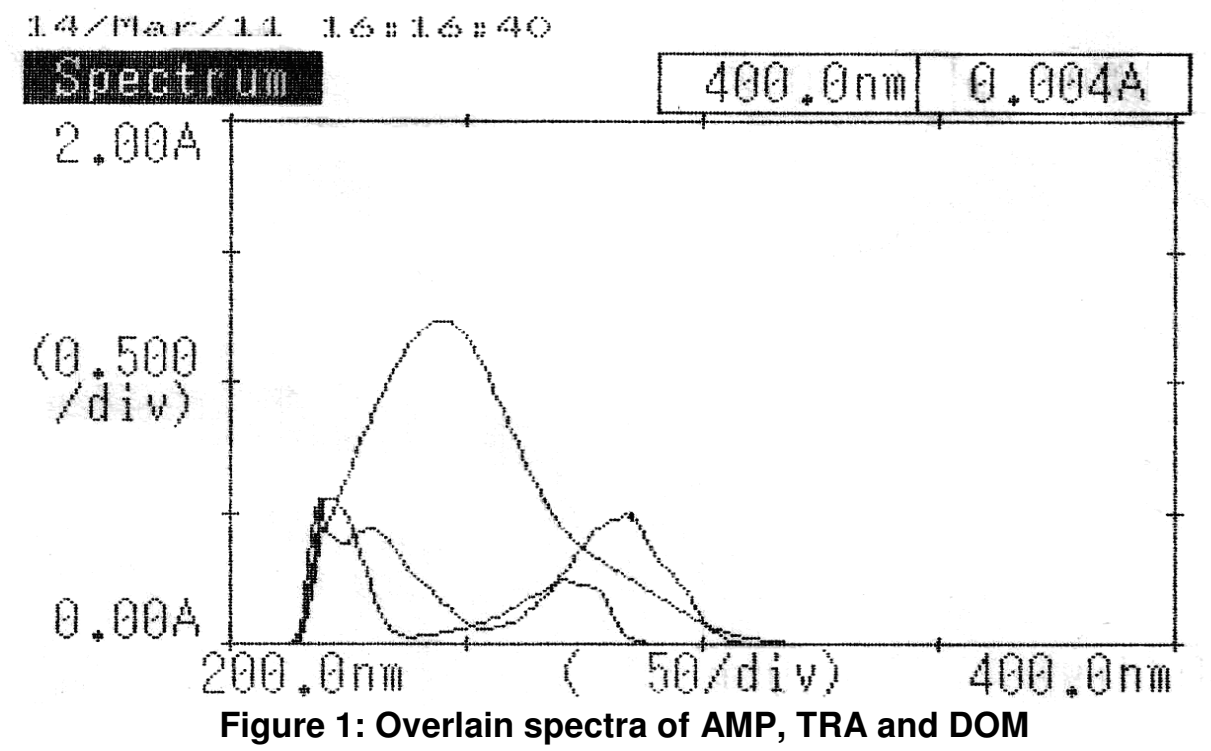

\section{Method A: Simultaneous Equation Method}

This method of analysis was based on the absorption of drugs (AMP, TRA and DOM) at the wavelength maximum of the each other (Davison et al, 2007). Three wavelengths selected for the development of the simultaneous equations were $244 \mathrm{~nm}, 271.5 \mathrm{~nm}$ and $284.5 \mathrm{~nm} ; \lambda_{\max }$ of all three drugs respectively. The absorbances of AMP, TRA and DOM were measured at all three selected wavelengths. The absorptivity values $E(1 \%, 1 \mathrm{~cm})$ were determined for three drugs at all selected wavelengths. These values were mean of five estimations.

The concentration of three drugs in mixture can be calculated by using following equations:

$$
\begin{aligned}
& C_{P C M}=\frac{A_{1}\left(a y_{2} a z_{3}-a z_{2} a y_{3}\right)-a y_{1}\left(A_{2} a z_{3}-a z_{2} A_{3}\right)+a z_{1}\left(A_{2} a y_{3}-a y_{2} A_{3}\right)}{a x_{1}\left(a y_{2} a z_{3}-a z_{2} a y_{3}\right)-a y_{1}\left(a x_{2} a z_{3}-a z_{2} a x_{3}\right)+a z_{1}\left(a x_{2} a y_{3}-a y_{2} a x_{3}\right)} \\
& C_{T R A}=\frac{a x_{1}\left(A_{2} a z_{3}-a z_{2} A_{3}\right)-A_{1}\left(a x_{2} a z_{3}-a z_{2} a x_{3}\right)+a z_{1}\left(a x_{2} A_{3}-A_{2} a x_{3}\right)}{a x_{1}\left(a y_{2} a z_{3}-a z_{2} a y_{3}\right)-a y_{1}\left(a x_{2} a z_{3}-a z_{2} a x_{3}\right)+a z_{1}\left(a x_{2} a y_{3}-a y_{2} a x_{3}\right)} \\
& C_{D O M}=\frac{a x_{1}\left(a y_{2} A_{3}-A_{2} a y_{3}\right)-a y_{1}\left(a x_{2} A_{3}-A_{2} a x_{3}\right)+A_{1}\left(a x_{2} a y_{3}-a y_{2} a x_{3}\right)}{a x_{1}\left(a y_{2} a z_{3}-a z_{2} a y_{3}\right)-a y_{1}\left(a x_{2} a z_{3}-a z_{2} a x_{3}\right)+a z_{1}\left(a x_{2} a y_{3}-a y_{2} a x_{3}\right)} .
\end{aligned}
$$


Where, $A_{1}, A_{2}$ and $A_{3}$ are the absorbances of sample at $244 \mathrm{~nm}, 271.5 \mathrm{~nm}$ and $284.5 \mathrm{~nm}$ respectively.

$\mathrm{ax}_{1}, \mathrm{ax}_{2}$ and $\mathrm{ax}_{3}$ are the absorptivity of AMP at $244,271.5$ and $284.5 \mathrm{~nm}$ respectively. $\mathrm{ay}_{1}, \mathrm{ay}_{2}$ and $\mathrm{ay}_{3}$ are the absorptivity of TRA at $244,271.5$ and $284.5 \mathrm{~nm}$ respectively. $a z_{1}, a z_{2}$ and $\mathrm{az}_{3}$ are the absorptivity of DOM at $244,271.5$ and $284.5 \mathrm{~nm}$ respectively.

\section{Estimation of AMP, TRA and DOM in tablet dosages form}

Twenty tablets (brand name-TRAMAZAC-PD) were taken and their average weight was determined, they were crushed to fine powder. The powder equivalent to $10 \mathrm{mg}$ of AMP was taken in $100 \mathrm{ml}$ volumetric flask and dissolved in $100 \mathrm{ml}$ of methanol/0.1 N HCl AR (1:2) with vigorous shaking for 5-10 minutes. The solution was then filtered through Whatman filter paper (\# 41), the filtrate contains $100 \mu \mathrm{g} / \mathrm{ml}$ of AMP. $2 \mathrm{ml}$ of sample stock solution was taken in a $10 \mathrm{ml}$ volumetric flask and $1.5 \mathrm{ml}$ of standard solution of DOM $(100 \mu \mathrm{g} / \mathrm{ml})$ and $3 \mathrm{ml}$ of standard solution of TRA $(100 \mu \mathrm{g} / \mathrm{ml})$ was added to it and final volume was made up with solvent used. The above mixture was analyzed at $244,271.5$ and $284.5 \mathrm{~nm}$ wavelengths and values of the absorbance were substituted in respective equations (Eqn. 1, 2 and 3) to obtain the content of AMP, TRA and DOM respectively. The result of analysis is mentioned in Table 1.

\section{Method B: multicomponent Analysis}

The multicomponent overlain spectrum of AMP, TRA and DOM is shown in Figure 2.

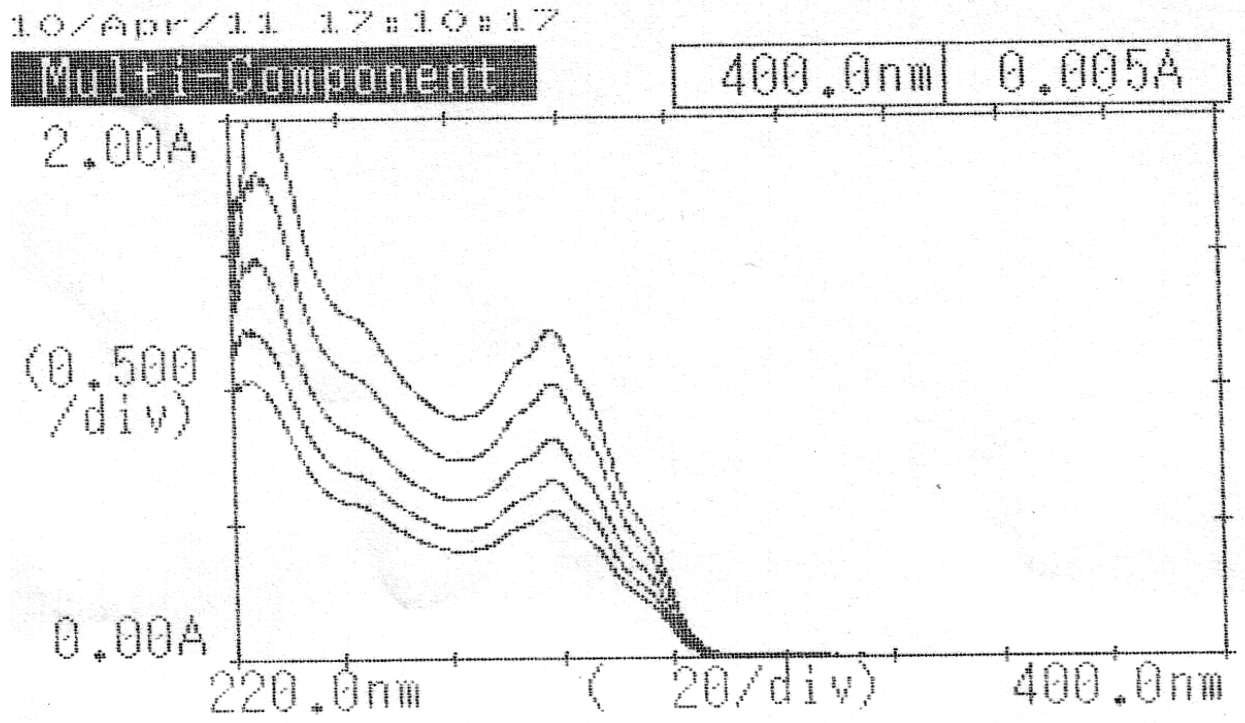

Figure 2: Multicomponent overlain spectra of AMP, TRA and DOM

The use of five mixed standards and four sampling wavelengths as $244 \mathrm{~nm}, 250 \mathrm{~nm}, 271.5 \mathrm{~nm}$ and $284.5 \mathrm{~nm}$ were found to serve the purpose of experimentation.

In this method, five mixed standards of AMP, TRA and DOM in the ratio of 1:5.1:2.03 having concentrations in $\mu \mathrm{g} / \mathrm{ml}$ of $6.7: 34.1: 13.54,8: 40.92: 16.25,10: 51.2: 20.31,12.5: 64: 25.40$ and 15:76.73:30.47 were prepared by appropriate dilution of the standard stock solutions and scanned in the region of $400 \mathrm{~nm}$ to $220 \mathrm{~nm}$ in the multi-component mode using the four sampling wavelengths as mentioned. Recording of the absorbance of the mixed standard solutions were processed by the instrument by means of matrix equations and were then corrected to determine the concentrations of all the drugs in the tablet sample solutions.

Tablet sample solution was prepared as described under method A. $1 \mathrm{ml}$ of sample stock solution was taken in a $10 \mathrm{ml}$ volumetric flask and $2 \mathrm{ml}$ of standard solution of DOM $(100 \mu \mathrm{g} / \mathrm{ml})$ and $5 \mathrm{ml}$ of standard solution of TRA $(100 \mu \mathrm{g} / \mathrm{ml})$ was added to it and final volume was made up with solvent used. The spectrophotometric analysis of the resulting solution was carried out using the multicomponent mode of the instrument. The result of analysis is mentioned in Table 1. 
Table 1: Results of Tablet Analysis.

\begin{tabular}{|c|c|c|c|c|c|}
\hline \multirow{2}{*}{ Brand } & \multirow{2}{*}{$\begin{array}{l}\text { Label Claim } \\
\text { mg/tablet }\end{array}$} & \multicolumn{2}{|c|}{ Amount found by method } & \multicolumn{2}{|c|}{$\%$ Recovery of method } \\
\hline & & $\mathbf{A}$ & B & $\mathbf{A}$ & B \\
\hline \multirow{3}{*}{ TRAMAZAC-PD } & AMP-325 & 324.25 & 327.95 & 99.77 & 100.91 \\
\hline & TRA-37.5 & 36.91 & 37.70 & 98.45 & 100.54 \\
\hline & DOM-10 & 10.01 & 10.12 & 100.12 & 100.02 \\
\hline
\end{tabular}

Where $A$ is simultaneous equation method and $B$ is multicomponent analysis.

\section{Validation of the Developed Methods}

Accuracy

To check the accuracy of the developed methods and to study the interference of formulation additives, analytical recovery experiments was carried out by standard addition method $(\mathrm{ICH}$, 1996). From that total amount of drug found and percentage recovery was calculated. The results and statistical data are reported in table 2.

Table 2: Statistical Analysis of Results of AMP, TRA and DOM.

\begin{tabular}{cccccccc}
\hline \multirow{2}{*}{ Method } & \multirow{2}{*}{ Drug } & \multicolumn{3}{c}{ Tablet formulation } & \multicolumn{3}{c}{ Recovery studies } \\
\cline { 3 - 8 } & & S.D. & C.O.V. & S.E. & S.D. & C.O.V. & S.E. \\
\hline \multirow{3}{*}{ A } & AMP & 0.323 & 0.324 & 0.144 & 0.234 & 0.236 & 0.104 \\
& TRA & 0.440 & 0.446 & 0.196 & 0.758 & 0.770 & 0.338 \\
& DOM & 0.965 & 0.963 & 0.431 & 0.698 & 0.695 & 0.312 \\
\hline \multirow{2}{*}{ B } & AMP & 0.305 & 0.302 & 0.136 & 0.621 & 0.614 & 0.277 \\
& TRA & 0.397 & $\mathbf{0 . 3 9 4}$ & 0.177 & 0.926 & 0.905 & 0.414 \\
& DOM & 0.584 & 0.576 & 0.261 & 0.558 & 0.561 & 0.249 \\
\hline
\end{tabular}

S.D. denotes standard deviation, C.O.V. is coefficient of variation and S.E. is standard error.

\section{Intermediate Precision (inter-day and intra-day precision)}

The intra and inter-day precision was calculated by assay of the sample solution on the same day and on different days at different time intervals respectively.

\section{Limit of detection (LOD) and Limit of quantitation (LOQ)}

The LOD and LOQ were separately determined based on the standard deviation of y-intercept of the calibration curve. The standard deviation of $y$-intercept and slope of the calibration curves were used to calculate the LOD and LOQ by using the equations $3.3 \sigma / \mathrm{s}$ for LOD and $10 \sigma / \mathrm{s}$ for LOQ, where $\sigma$ stands for standard deviation of $y$-intercept and s stands for slope of the calibration curve.

\section{RESULTS AND DISCUSSION}

\section{Calibration curve}

The linear regression equations obtained were absorbance at $244 \mathrm{~nm}=0.1351 \mathrm{x}+0.0307$ (For AMP, $\left.r^{2}=0.9991\right)$, at $271.5 \mathrm{~nm}=0.0061 \mathrm{x}+0.0265\left(\right.$ For TRA, $\left.r^{2}=0.9997\right)$, at $284.5 \mathrm{~nm}=0.0557 \mathrm{x}+$ $0.0395\left(r^{2}=0.9991\right)$.

\section{Accuracy}

The validity and reliability of proposed methods were assessed by recovery studies by standard addition method. The means of \% recovery (\% RSD) were found to be $<1.0$ for both two methods. These results revealed that any small change in the drug concentration in the solution could be accurately determined by the proposed analytical methods.

Intermediate Precision (inter-day and intra-day precision)

The intra and inter-day precision was calculated by assay of the sample solution on the same day and on different days at different time intervals respectively. The results are presented in Table 3.

\section{LOD and $L O Q$}

The value of LOD and LOQ were $0.060 \mu \mathrm{g} / \mathrm{ml}, 0.187 \mu \mathrm{g} / \mathrm{ml}$ for AMP, $0.992 \mu \mathrm{g} / \mathrm{ml}, 3.104 \mu \mathrm{g} / \mathrm{ml}$ for TRA and $0.241 \mu \mathrm{g} / \mathrm{ml}, 0.754 \mu \mathrm{g} / \mathrm{ml}$ for DOM for method A and B both. 
Table 3: Result of Intraday, Interday Study.

\begin{tabular}{cccccc}
\hline \multirow{2}{*}{ Method } & \multirow{2}{*}{ Drug } & $\begin{array}{c}\text { Intraday precision } \\
\text { \% COV }(\mathbf{n}=\mathbf{3})\end{array}$ & \multicolumn{3}{c}{ Interday precision \% COV $^{\text {C }}$} \\
\cline { 4 - 6 } & & 0.564 & Day 1 $^{\text {a }}$ & Day 2 $^{\text {a }}$ & Day 3 $^{\text {a }}$ \\
\hline \multirow{2}{*}{ A } & AMP & 0.365 & 0.443 & 0.368 & 0.384 \\
& TRA & 0.981 & 0.650 & 0.723 & 0.461 \\
& DOM & 0.421 & 0.357 & 0.387 \\
\hline \multirow{2}{*}{ B } & AMP & 0.621 & 0.753 & 0.377 \\
& TRA & 0.667 & 0.187 & 0.412 & 0.498 \\
& DOM & 0.547 & 0.934 & 0.551 & 0.368 \\
\hline
\end{tabular}

${ }^{a}$ Mean of five determinations, COV denotes Coefficient of Variance

\section{Estimation of formulation}

The assay value of AMP, TRA and DOM for method A was 99.77, 98.45 and 100.12 respectively with standard deviation $<1.0$ while for method $B$ was found to be 100.91, 100.54 and 100.02 respectively with standard deviation $<1.0$ (Table 1). Assay values of formulation were same as mentioned in the label claim indicating that the inference of excipient matrix is insignificant in estimation of AMP, TRA and DOM by two proposed methods.

\section{CONCLUSION}

The proposed methods were found to be simple and rapid for routine analysis of all three drugs in combined dosage forms as compared to conventional separation techniques.

The method $A$, simultaneous equation method, is a simple method. It requires measurement of absorbance at three wavelengths $244 \mathrm{~nm}, 271.5 \mathrm{~nm}$ and $284.5 \mathrm{~nm}$ and few simple calculations. Standard deviation values ( 0.323 for AMP, 0.440 for TRA and 0.965 for DOM) were satisfactory, keeping in view the amount of drug in the formulation. Recovery studies lying between $98-102 \%$ were indicative of the accuracy of the method.

The method B, multicomponent analysis, is based on principle of over determination. In this method, the instrument is preprogrammed to collect and compile the spectral data from the scan of standards and produces the result by matrix calculations. Five mixed standard and four sampling wavelengths were selected through rational experimentation keeping in view the amount of drugs in the formulation and absorptivity coefficients of all three drugs. The method requires no manual calculations, produces comparable results to the first method and is more suitable as compared to method $A$. In both method $A$ and $B$, standard addition of TRA and DOM have been done to improve absorbance contribution which improves accuracy of estimation.

\section{ACKNOWLEDGMENT}

The authors are thankful to Ranbaxy Laboratories Pvt. Ltd. Dewas, M.P., India and Zest pharma pvt. Ltd., Indore, M.P., India for providing gift samples of AMP, TRA and DOM respectively. One of the authors, Mr. Vikas Jain is thankful to All India Council for Technical Education (AICTE) for providing junior research fellowship.

\section{REFERENCES}

British Pharmacopoeia (2002) Vol. II, The British Pharmacopoeia Commission, London, pp. 2367, 2119.

Celma C., Allué J. A., Pruñonosa J., Peraire C. and Obach R. (2000) Simultaneous determination of paracetamol and chlorpheniramine in human plasma by liquid chromatography- tandem mass spectrometry. J Chromatogr A, 870: 77-86.

Davison A.G., Beckette A.H., Stenlake J.B. (1997) Practical Pharmaceutical Chemistry, CBS Publishers and distributors, New Delhi, p. 275.

Gandhimathi M, Ravi TK, Shukla N. and Sowmiya G, (2007) Validated high performance thin layer chromatography method for simultaneous estimation of ofloxacin and ornidazole in tablet dosage form. Indian J. Pharm. Sci, 69: 145-147. 
Garg G., Saraf S. and Saraf S. (2007). Simultaneous estimation of aceclofenac, paracetamol and chlorzoxazone in tablets. Indian J. Pharm. Sci, 69: 692-694.

Geng-Chang Y., Ming-Thau S., Chia-Lin Y., Ya-Wen W., Cheng-Hsiung L. and Hsiu-O H., (1999) High-performance liquid chromatographic method for determination of tramadol in human plasma. J.Chromatogr. B: Biomed. Appl., 723: 247-253.

Gopinath R, Rajan S, Meyyanathan SN, Krishnaveni N and Suresh B, (2007) A RP-HPLC method for simultaneous estimation of paracetamol and acelofenac in tablets. Indian J. Pharm. Sci, 69: 137-140.

ICH Q2B: Text on Validation of Analytical Procedures-Methodology Step-4, (1996) Consensus Guidelines, and ICH Harmonized Tripartite Guidelines.

Indian Pharmacopoeia, (1996) Vol. II, The controller of publication, Govt. of India, Ministry of Health and family welfare, New Delhi, p. 554.

Küçük A. and Kadıoğlu Y., (2005) Determination of tramadol hydrochloride in ampoule dosage form by using UV spectrophotometry and HPLC-DAD methods in methanol and water media. II Farmaco 60: 163-169.

Martindale (2002), The Complete Drug Reference, The pharmaceutical Press, London, p. 71.

Puranik M., Hirudkar A., Wadher SJ and Yeole PG, (2006). Development and validation of spectrophotometric methods for simultaneous estimation of tramadol hydrochloride and chlorzoxazone in tablet dosage form. Indian J. Pharm. Sci., 68: 737-739.

Srinivasan KK, Alex J., Shirwaikar AA, Jacob S., Sunil K. MR and Prabu SL, (2007). Simultaneous derivative spectrophotometric estimation of tramadol and aceclofenac with paracetamol in combination solid dosage form. Indian J. Pharm. Sci, 69: 540-545.

The Merck Index (2001), Merck \& co. Inc, Whitehouse Station, NJ, p. 3452.

Tripathi K.D. (2004), Essentials of Medical Pharmacology, Jaypee Brothers Medical Publishers (P) Ltd., p. 426. 